\title{
Acute care physical therapy management of a 69-year-old female following re-operative aortic valve replacement and tricuspid valve repair: A case report
}

\author{
Natalia Fernandez ${ }^{1}$ and Jennifer Blackwood ${ }^{2 *}$ \\ ${ }^{1}$ Physical Therapy Department, Michigan Medicine, Ann Arbor, MI, USA \\ ${ }^{2}$ Physical Therapy Department, University of Michigan-Flint, 2157 William S. White Building, 303 East Kearsley Street, Flint, MI 48502-1950, USA
}

\begin{abstract}
Background and purpose: Senile aortic stenosis commonly remains asymptomatic until the sixth or seventh decade of life. For those with AS who undergo aortic valve replacement, early mobility and exercise have been associated with improved functional outcomes. However, case reports describing the physical therapy management including the use of validated tools to assess and monitor function in those with AS status post valve replacement is limited. This case report describes the physical therapy (PT) management following re-operative cardiac surgery for aortic valve replacement and tricuspid valve repair during the inpatient acute care hospital stay.
\end{abstract}

Case description: A 69-year-old female with past medical history of severe aortic stenosis, hypertension, severe tricuspid regurgitation, paroxysmal atrial fibrillation (AF) who underwent aortic valve replacement and tricuspid valve repair followed by a 6-day intensive care unit stay secondary to complications. PT examination was initiated on post-operative day (POD) 1 and included assessments of function (Functional independence measure (FIM)), mobility (30 second chair rise (SCR) and gait speed), and fatigue (fatigue severity scale (FSS)) to guide PT intervention.

Outcomes: Significant improvements in the patient's FIM, 30 SCR, gait speed and FSS were achieved from examination to discharge.

Discussion: Improvements on selected measures were clinically significant for this case, but standardized values for improvement are not reported in the literature and should be investigated further.

\section{Background and purpose}

Aortic Stenosis (AS) is caused by restricted opening of the aortic valve and when prolonged leads to left ventricular systolic dysfunction and dilatation and increased pressure in the lungs and the right side of the heart [1]. Senile calcific AS which represents the most common form of acquired valvular heart disease in the United States is an insidious and progressive disease characterized by a long latency period followed by rapid progression after symptom onset, resulting in high rates of morbidity and mortality among untreated patients. Despite gradual fibrosis and progressive stenosis, most adults remain asymptomatic until their sixth to seventh decade of life [2].

Clinical manifestations of AS include dyspnea and/or syncope on exertion, angina pectoris, light headedness, systolic ejection murmur and sudden death [1]. Symptoms have an insidious onset and are highly variable among adults with similar degrees of valve stenosis. Often, a subtle decrease in exercise tolerance is reported as the first symptom, however by the time this develops, AS is quite advanced [3]. Although exercise will not improve the mechanical function of the aortic valve, improvements in submaximal cardiac capacity can occur. Exercise stress testing is recommended by the American Heart Association and American College of Cardiology to be performed in the asymptomatic adult with severe AS when the history is unclear in order to assess exercise-induced symptoms or an abnormal blood pressure response. However, in those with symptomatic severe AS exercise stress testing is absolutely contraindicated and therefore, the use of functional measures should be employed in those with AS [4].
Improved quality of life, increased life span, and improved outcomes have been reported in adults status post aortic valve replacement procedures [5]. Initiation of early mobility and exercise while in the intensive care unit (ICU) has been reported to be safe, decreases time required to meet mobility milestones and reduces the ICU and hospital length of stay [6,7]. Exercise testing and prescription in the immediate post-operative, post discharge and maintenance stages is important after valve replacement for improved overall functional mobility. In the acute care setting, results gathered from objective measures of physical function help determine whether phase 1 cardiac rehabilitation in the hospital is appropriate. Clinicians need to be able to interpret real time data and make decisions surrounding complex medical information to determine the patient's appropriateness for participation in therapy including whether the patient demonstrates an appropriate hemodynamic response [8]. For those with AS, exercise selection and progression for each individual must be performed using objective measures in addition to monitoring symptoms of cardiac decompensation during exercise. Beyond exercise monitoring, information from the medical chart such as lab values, radiographs, and

Correspondence to: Jennifer Blackwood PT, PhD, GCS, Physical Therapy Department, University of Michigan-Flint, 2157 William S. White Building, 303 East Kearsley Street, Flint, MI 48502-1950, USA; E-mail: jblackwo@umflint.edu

Received: February 07, 2018; Accepted: February 24, 2018; Published: February 28,2018 

case report

cardiac monitoring tests must be reviewed to guide decision making for selected physical therapy interventions to promote improved outcomes. Due to the added complexity of the medical management of adults with AS after valve replacement, objective data from validated measures should be used to measure progress. However, literature describing the use of standardized functional measures to guide the physical therapy management of cardiac patient's status post aortic valve replacement and tricuspid valve repair is limited. Therefore, the purpose of this case report is to describe the acute care physical therapy management of a 69-year-old female following re-operative cardiac surgery for aortic valve replacement and tricuspid valve repair.

\section{History, Systems review}

$\mathrm{KB}$ is a 69 -year-old female, whose past medical history includes a history of severe aortic stenosis, hypertension, severe tricuspid regurgitation, paroxysmal atrial fibrillation, pulmonary embolism in 2008, osteoarthritis, ascending aortic aneurysm repair in 2009, right humeral fracture, T12 compression fracture, and chronic kidney disease stage 1 and presented with New York Heart Association classification II-III. Five months prior to hospitalization an echo transesophageal revealed severe AS in the bicuspid aortic valve. Cardiac catheterization performed four months prior to surgical repair indicated a mildly elevated right ventricular filling pressure, severe aortic stenosis, and mild non-obstructive coronary artery disease, severe tricuspid regurgitation. Left ventricular systolic function and cardiac output was considered normal.

Prior to hospitalization, KB lived independently in her home with her husband. She was active at home, walked half a mile daily at a brisk pace and kayaked half a mile once a week, weather permitting. In the two months prior to hospitalization, she experienced dyspnea with stair climbing and occasional heart palpitations. Upon admission, she was taking the following medications: metoprolol tartrate $25 \mathrm{mg}$ tablet two times per day, acetaminophen $500 \mathrm{mg}$ as needed, aspirin $81 \mathrm{mg}$ delayed release daily, cyclobenzaprine $10 \mathrm{mg}$ every eight hours, furosemide 20 mg once daily, hydralazine $25 \mathrm{mg}$, triamterene-hydrochlorothiazide 37.5 - $25 \mathrm{mg}$, loratadine $10 \mathrm{mg}$ as needed, multivitamin tablet once daily, potassium once daily and warfarin $2.5 \mathrm{mg}$ tablet once daily. $\mathrm{KB}$ was admitted to a 24 bed adult cardiovascular intensive care unit (CICU) of the University of Michigan Healthcare system (UMHS) and underwent an elective aortic valve replacement and a tricuspid valve repair via median sternotomy. Following surgery, KB was transferred to the CICU and extubated the following day. Her post-operative complications included atrial fibrillation with rapid ventricular response. She received three amiodarone boluses and was started on a drip for 24 hours. KB provided consent for information to be used for this case study.

\section{Examination}

KB's activity orders were bed rest until hemodynamically stable and then advance activity as tolerated. KB was restricted from pushing, pulling or lifting anything $>10$ pounds with her upper extremities. Parameters set by medical team to alert the physician included: $\mathrm{HR}<60$ or $>120, \mathrm{RR}<10$ or $>28, \mathrm{SpO} 2<92 \%, \mathrm{SBP}<90$ or $>150, \mathrm{DBP}<50$ or $>95$, $\mathrm{MAP}<60$ or $>100, \mathrm{CVP}<4$ or $>18$. KB weighed 144 pounds with a height of 5 feet 2 inches for a BMI of $26.3 \mathrm{~kg} / \mathrm{m}^{2}$. At physical therapy evaluation, the patient's medications included: acetaminophen $650 \mathrm{mg}$ oral every 6 hours, aspirin $325 \mathrm{mg}$ oral once daily, bisacodyl $10 \mathrm{mg}$ rectal once, docusate sodium $100 \mathrm{mg}$ oral twice daily, heparin $5 \mathrm{~mL}$ intravenous (IV) once daily, insulin lispro 0-12 units subcutaneous three times a day, vancomycin 1,000 mg IV once daily, continuous infusions: dextrose 5
$\%$ - sodium chloride $0.45 \% 20 \mathrm{~mL} / \mathrm{hr}$, insulin infusion $1.12 \mathrm{~mL} / \mathrm{hr}$, milrinone infusion $0.25 \mathrm{mcg} / \mathrm{kg} / \mathrm{min}$, norepinephrine infusion and sodium chloride $10 \mathrm{~mL} / \mathrm{hr}$. Findings on chest X-ray included bibasilar atelectasis and possible small pleural effusions, mild pulmonary edema and mildly enlarged cardio pericardial silhouette. Relevant lab values on chart review included arterial blood gas included $\mathrm{pH}$ : 7.39, pCO2: $37 \mathrm{mmHg}$, pO2: $110 \mathrm{mmhg}, \mathrm{HCO} 3: 21.9 \mathrm{mmol} / \mathrm{L}$, Potassium: 4.0 mmol/L, hemoglobin: 7.9 (L), hematocrit: $22.0(\mathrm{~L})$ and white blood cell: $8.2 \mathrm{~K} / \mathrm{MM} 3$.

On examination $\mathrm{KB}$ was medically stable, alert and oriented to person, place, time and situation, and willing to participate in physical therapy. Towards the end of the examination and intervention the patient did report feeling cloudy from medication. Mini-Cog test was negative for cognitive impairment. The findings on neuromuscular screen included generalized muscle weakness, decreased range of motion and balance deficits with details provided in Table 1. The patient demonstrated decreased upper extremity strength, but was not formally assessed secondary to midline precautions. Manual muscle testing revealed decreased strength in bilateral lower extremities (415) for hip flexion and extension, hip abduction, knee flexion and knee extension. The cardiovascular and pulmonary systems screen included a resting heart rate of 91 beats per minute, irregular rhythm atrial and ventricle paced with occasional ectopy (premature ventricular contractions), BP $114 / 63 \mathrm{mmHg}$ and oxygen saturation was $96 \%$ on 6 liters of supplemental oxygen via nasal cannula. Lung auscultation revealed fine crackles throughout all fields. $\mathrm{KB}$ had shallow and irregular respiration and a weak and nonproductive cough. Her best effort was three repetitions to $250 \mathrm{ml}$ on the incentive spirometer. Pitting edema $(2+)$ was found in both lower extremities distally to the knee. She reported $2 / 10$ pain at the midline incision, chest tube sites and throat on the $0-10$ verbal numeric rating scale. The numeric rating pain scale is an 11-point scale from $0-10$ with 0 indicating no pain and 10 being the worst pain imaginable. The scale has established reliability and validity and MCID established in different populations. On integumentary screen, the midline sternal incision was covered with dressing. She had multiple lines and tubes including a pulmonary artery catheter, arterial line, chest tubes, peripheral IV lines and urinary catheter in place which limited screening of musculoskeletal system.

The Functional Independence Measure (FIM) consists of 18 items divided in to 6 sections: self-care, sphincter control, mobility, locomotion, communication and social cognition. These items are further categorized into 2 over-arching dimensions: life habits and ability. FIM is reliable, valid, standardized, and provides comprehensive assessment of a person's functional deficits while in a hospital setting $[9,10]$. Baseline mobility FIM scores on initial examination were bed mobility:1, transfers:1, gait:1 and stairs: 0 . The sit to stand test (STS) is a multidimensional test of lower limb strength but also of variables such as sensorimotor, balance, and psychological parameters [8]. In the 30 second chair stand test (CST), the patient was able to complete 3 repetitions a baseline. Table 1 provides an overview of the initial examinations conducted.

\section{Clinical impression}

KB was medically stable, had appropriate activity orders, was able to follow the required activity precautions for safe participation in physical therapy and was considered a good candidate for PT intervention. Physical therapy intervention is beneficial for the various systems contributing to her impaired functional independence and activity tolerance. Systematic synthesis of the multiple tests and measures from the history, systems review and examination confirmed 
Table 1. Systems Review and Examination.

\begin{tabular}{|c|c|}
\hline $\begin{array}{l}\text { Relevant Medical Tests \& } \\
\text { Measures }\end{array}$ & $\begin{array}{l}\text { Lab tests: pH 7.39, pCO2 } 37 \mathrm{mmhg} \text {, pO2 } 110 \mathrm{mmhg}, \mathrm{HCO} 321.9 \mathrm{mmol} / \mathrm{L}, \mathrm{K}+4.0 \mathrm{mmol} / \mathrm{L}, \mathrm{HGB} 7.9(\mathrm{~L}), \mathrm{HCT} 22.0(\mathrm{~L}), \mathrm{WBC}) 8.2 \mathrm{~K} / \mathrm{MM} 3 \text {. } \\
\text { Chest X- ray: bibasilar atelectasis and possible small pleural effusions, mild pulmonary edema and mildly enlarged cardio pericardial silhouette. }\end{array}$ \\
\hline \multicolumn{2}{|l|}{ Tests and Measures } \\
\hline $\begin{array}{l}\text { Arousal, Attention, Communication } \\
\& \text { Cognition }\end{array}$ & $\begin{array}{l}\text { Orientation Oriented x4 (person, place, time and situation); Alert ,Follows Commands and Answers Questions } 100 \% \text { of the time, Behavioral/ } \\
\text { Emotional Responses Age appropriate. Mini-cog test = able to recall } 3 \text { words and normal clock drawing = negative for cognitive impairment. } \\
\text { Glasses for reading. }\end{array}$ \\
\hline Pain & Numeric pain scale $0-10.2 / 10$ midline incision, chest tube sites and throat. \\
\hline Cardiovascular \& Pulmonary & $\begin{array}{l}\text { Vitals: HR } 91 \text { AV paced, BP 114/63, SPO2 98\% on } 6 \text { O2 NC Supplemental Oxygen, Rhythm/Pattern (Respiratory) rate irregular; depth regular, } \\
\text { Breath Sounds: fine crackles throughout all fields. Cough weak and non productive. Spirometer }-250 \mathrm{ml} \text { x } 3 \text { reps. }\end{array}$ \\
\hline Integument & midline sternal incision covered with dressing, PA catheter, chest tubes, A line, peripheral line. \\
\hline Sensation & Denies paresthesia, intact to light touch and pressure in all 4 extremities \\
\hline Circulation & $2+($ Mild) pitting edema in left and right foot and leg to knee \\
\hline Range of Motion & $\begin{array}{l}\text { All } 4 \text { extremities active ROM mildly impaired. R and L shoulder ROM limited grossly in abduction and flexion } 130 \text { (limited secondary to } \\
\text { discomfort and fear of movement), B LE limited in end range hip flexion from tubes, and knee flexion and extension secondary to edema. }\end{array}$ \\
\hline Muscle Performance & $\begin{array}{l}\text { B UE strength not formally assessed secondary to midline precautions, grossly at least } 3+/ 5 \text { in major muscle groups. B LE } 4 / 5 \text { hip flexion/ } \\
\text { extension, hip abduction, knee flexion and extension. }\end{array}$ \\
\hline Motor function & WNL for functional activities, otherwise not assessed \\
\hline Functional mobility & Bed mobility - supine to sit - NA, sit to supine min A x 2, sit to stand supervision, ambulation CGA and assist for line/ tube management. \\
\hline Balance & $\begin{array}{l}\text { Sitting Balance: Good, Sit-to-stand Balance: Contact guard, Standing Balance: Static and dynamic: Contact guard, Tandem Stance negative able } \\
\text { to tolerate }>10 \text { secs, Romberg negative }\end{array}$ \\
\hline Gait & $\begin{array}{l}\text { Decreased cadence; Increased time in double stance; Decreased step length; Decreased toe-to-floor clearance; Decreased weight-shifting ability; } \\
\text { Narrow base of support; Decreased heel strike. }\end{array}$ \\
\hline Aerobic Capacity & $\begin{array}{l}\text { Able to complete 5-10 repetitions each of midline exercise. Limited tolerance, required multiple rest breaks between exercise secondary to fatigue } \\
\text { and increased time required for recovery. Counting talk test } 11 \text { at rest. RPE - hard at peak. Pt was able to tolerate } 30 \text { second sit to stand ( } 30 \text {-s } \\
\text { CST) }=3 \text {. Able to ambulate } 6 \text { feet }+6 \text { side steps. }\end{array}$ \\
\hline
\end{tabular}

the physical therapy diagnosis from the Guide to Physical Therapist Practice [11]. Functional limitation in the following categories were identified including impaired ability to transfer/change position and impaired gait, locomotion, and self-care secondary to impairments in cardiac pump function, aerobic capacity/sustained activity tolerance and ventilation and respiration/gas exchange. Physical therapy interventions to address her identified deficits was considered to be beneficial to the patient's recovery. Further assessments throughout physical therapy intervention included regular assessments of RPE, FIM, 30 second chair rise test, gait speed, fatigue severity scale and Kansas City Cardiomyopathy questionnaire.

\section{Intervention}

The typical cardiac rehabilitation protocol starts in the hospital and continues after discharge in a supervised setting eventually transitioning to a home-based program [12]. In this institution, physical therapy initiates phase 1 cardiac rehabilitation in the ICU using a multidisciplinary approach in collaboration with other health care providers. Physical therapy intervention was initiated on POD 1 and was performed 3 times per week for a total of six PT visits.

The patient was screened for appropriateness of participation in physical therapy following surgery. Laboratory values were monitored daily including hemoglobin, white blood cell count, platelet count, anti-coagulation values, calcium, potassium, sodium, magnesium and chloride. The guidelines used for PT participation were hemoglobin $>7.0 \mathrm{gm} / \mathrm{dl}$, platelet count $>10,000$ cells $/ \mathrm{m}^{3}$, white blood cell count between $5-10,000$ leukocytes $/ \mathrm{mm}^{3}$ per acute care physical therapy guidelines in this institution [13]. The hemodynamic parameters set by the medical team were followed during the PT session. Interventions were modified based on patient report on RPE scale (target to remain within the range of 11-13), pain, negative signs, abnormal hemodynamic parameters and any negative symptoms including but not limited to light headedness or chest discomfort.

Physical therapy interventions focused on the patient's identified impairments and functional limitations from the initial and follow up examinations. Since sternal disruption occurs in $2 \%-8 \%$ of patients with median sternotomy, therapeutic interventions were focused on instructing the patients receive providing instructions in sternal precautions including the appropriate transfer techniques from supine to sitting position, to rise from a chair using her legs rather than pushing down with the arms as this could add stress to the incision [14]. The patient was also instructed on hugging a pillow when coughing to help to brace the incision to reduce the disruptive forces on the incision [15]. Education was provided on importance of continued adherence to precautions after discharge to minimize sternal stress, pain and for improved healing. ${ }^{15}$ Further education focused on education regarding posture correction, safety, fall prevention, RPE scale and integration to guide activity, signs and symptoms of exercise intolerance, safe exercise parameters, home exercise program and progression. Table 2 provides a summary of the main physical therapy interventions provided during the episode of care.

Muscle strengthening focused on sit-to stand transfers exercise. This was guided by her results obtained in her 30 second chair rise test to develop her knee and hip extension strength and to address her difficulty rising from a chair while maintaining her midline precautions. General musculoskeletal strength and ROM deficits identified were addressed through a midline exercise program which included shoulder shrugs, circles, forward arm raises, abduction, pectoral strength, trunk side bending and twists, deep breathing exercises and splinted coughing. Cardiopulmonary endurance was addressed through gait training and a progressive walking program focusing on improving the patient's gait speed. Other intervention provided to the patient were similar to those described in other ICU literature and included therapeutic activity, exercise, transfer, balance and gait training $[16,17]$.

During a PT session on POD $8, \mathrm{~KB}$ complained of increased dizziness with head position changes during transfer training interventions for safe bed mobility training. She described the vertigo as transient which resolved in less than one minute. She reported having episodes in her past which were triggered by similar head movements. The physical therapist evaluated the patient for benign 
Fernandez N (2018) Acute care physical therapy management of a 69-year-old female following re-operative aortic valve replacement and tricuspid valve repair: A case report

Table 2. Tests and measures by treatment date.

\begin{tabular}{|c|c|c|c|c|c|c|}
\hline Measures & Initial - POD 1 & POD 2 & POD 3 & POD 6 & POD 7 & POD 8 \\
\hline FIM -transfers & 1 & 1 & 1 & 1 & 4 & 4 \\
\hline FIM - gait & 1 & 1 & 2 & 1 & 1 & 5 \\
\hline FIM - stairs & 0 & 1 & 1 & 1 & 1 & 2 \\
\hline 30-s CST & 3 & & & 6 & & 8 \\
\hline Gait speed & $0.30 \mathrm{~m} / \mathrm{s}$ & & & & $0.37 \mathrm{~m} / \mathrm{s}$ & $0.55 \mathrm{~m} / \mathrm{s}$ \\
\hline ABC & $66.8 \%$ & & & & & $72.50 \%$ \\
\hline FSS & & 49 & 47 & & & 42 \\
\hline KCCQ-12 & & & 45 & & & \\
\hline Tinetti & & & & & & 22 \\
\hline
\end{tabular}

paroxysmal positional vertigo (BPPV). The patient had a positive vertical and torsional component nystagmus to the left ear on the DixHallpike test and was symptomatic. Repositioning maneuvers were declined after symptoms resolved. KB was allowed to rest in bed and follow up visit was not possible. The PT provided KB with education on vestibular rehabilitation that could be either self-administered or with PT for the initial and follow up treatment in the formal vestibular rehabilitation setting [18]. The patient was also educated regarding BPPV reoccurrence and safety concerns. KBs physicians were notified of findings and recommendation for vestibular rehabilitation.

\section{Outcomes}

The outcome measures utilized in this case report during initial and follow up examinations were useful to guide the plan of care for setting appropriate goals and to provide evidence to support progress from physical therapy interventions. The FIM provides an objective assessment of rehabilitative potential and success and was assessed at all PT sessions [19]. FIM scores improved significantly from baseline examination to discharge with scores for bed mobility: 4 , transfers: 4 , gait: 5 and stairs: 2 .

The 30-second chair rise test is a more appropriate functional lower limb endurance assessment instrument for older adults categorized with higher physical functional abilities [8]. Reliability and validity has been established in the geriatric population but has not been researched in the post cardiac surgical patient population or in the acute care setting. The scores on KB's sit to stand increased significantly from examination to day of discharge from 3 to 8 repetitions, which is beyond the MCID established for patients of similar age with hip osteoarthritis [8]. KB remained below her age reported average at the time of discharge. She was educated on the normative data for her age and was determined to work towards improving her scores.

The Kansas City Cardiomyopathy questionnaire (KCCQ) is a cardiac disease specific quality of life measure which consists of 23 items and has a 2-week time frame for the patient to self-report. It has an established minimal clinically important difference of less than or equal to 5 . The various domains in the KCCQ like the physical limitations and symptoms stability have been correlated with the 6MWT and NYHA classification system [20]. Since scores of $<50$ on both the KCCQ overall summary and self-efficacy scales have been associated with a significantly higher risk of mortality and re-hospitalization the physical therapist choose to administer the KCCQ on POD 2 for further examination [20]. Lower mean KCCQ symptom scores have been reported among patients admitted to the hospital and on POD $2 \mathrm{~KB}$ scored 45 on the KCCQ [20]. Notably on this day the patient was experiencing increased dyspnea and a new onset of atrial fibrillation with RVR. Based on the results obtained from the administration of the KCCQ the information was used to provide education related to the intensity of activity and exercise to help avoid further exacerbation of symptoms and to modify the established POC. Secondary to time constraints follow up a KCCQ was not administered to the patient.

Fatigue is highly prevalent among both the chronically ill and acutely hospitalized individuals and is associated with functional limitations and mortality. The fatigue severity scale (FSS) was administered to KB [21-23]. FSS measures the impact of fatigue on specific types of function rather than the intensity of fatigue-related symptoms [24]. The FSS has good test retest reliability and is sensitive to change with time. Reliability and validity has been established in the geriatric population but the MCID has not been reported [24]. KB's scores improved from 55 on examination to 42 at the time of discharge and her scores fluctuated with her symptoms of dyspnea and her RPE ratings.

Walking speed has been suggested to be regarded as a vital sign [25] with studies reporting improvements in gait speed even over short courses of therapy during acute hospital stays [26,27]. Usual gait speed was measured using the $10 \mathrm{MWT}$ through the course of physical therapy. Gait speed improved from $0.30 \mathrm{~m} / \mathrm{s}$ on initial examination to $0.55 \mathrm{~m} / \mathrm{s}$ on discharge from therapy, which exceeded the $0.05 \mathrm{~m} / \mathrm{s}$ established meaningful improvements in walking speed and the $>0.1 \mathrm{~m} / \mathrm{s}$ change which would predict her well-being, [28,29] but was still considerably slower than mean gait speeds reported in women aged 60-69 [27].

KB's post-operative recovery was complicated by atrial fibrillation with rapid ventricular response and respiratory complications with increased oxygen requirements which increased her length of stay in the CICU to 6 days, which is longer than the average stay for similar procedures (2-3 days). She was able transfer to the cardiac step down unit on post-operative day 6. Despite this longer ICU, KB obtained clearance for discharge home on POD 8 with recommendations for follow up further outpatient cardiac rehabilitation.

\section{Discussion}

Current guidelines from the US Department of Health and Human Services state that all adults older than 65 years should participate in 150 minutes of moderate aerobic exercise per week [30]. A multidisciplinary rehabilitation program should therefore be available for all patients undergoing valve surgery to initiate an exercise program while in the hospital [31]. Rehabilitation professionals working in acute care need to consult with other members of the medical team to fully explore the risk versus benefits of physical therapy intervention, to assist with the development of facility policies, procedures, and/or protocols for clinical decision making to determine the aggressiveness of physical therapy intervention acutely following surgery. The patient in this case report benefitted from the focused examination as the data, which was provided to the patient helped motivate her to work towards her goals. Thus it is integral for the physical therapist to complete a 

case report

comprehensive examination whenever possible using the most appropriate tests and measures.

The 30-second chair rise has excellent test-retest, interrater and intrarater reliability among community dwelling elderly, including those with CVD. Validity of the 30-second chair rise has been established using leg strength measurements with a leg press. With this in mind, $\mathrm{KB}$ was well below average compared to other community dwelling elderly, including some with CVD, as the average 30 -second chair rise for this population was 12.7 for females. Though it is minor, it has been questioned whether or not the 30 second chair rise is sensitive enough for all levels of activity or ability of older adults, including those status post cardiac valve replacement surgery [32]. However, as standard measures of functional lower extremity strength, rehabilitation professionals should consider use of the 30-second chair rise order test with the understanding the future studies are needed to establish normative data in women with CVD and with those in an acute care setting.

FIM scores are widely used by health care professionals to assess functional status; however data reported to determine clinically important improvements on the FIM have predominantly been performed in older adults with stroke and not those primarily with CVD [33-35]. As a result, normative data must be used with caution when making comparisons for this case; however, this further highlights the need for assessing FIM scores by diagnostic category to aid with treatment and discharge planning [36]. The FIM motor subscale scores and the 10-item Barthel Index has reported to be highly correlated [37]. It is believed that the improvements in FIM scores are a result of improvements in motor function. An improvement in mean FIM scores of 3.3 points was reported in a group of older adults residing in the post-acute geriatric and rehabilitation unit within a hospital [34]. KB's results improved in all areas with the greatest improvement in transfers ( 1 to 4 ) and gait ( 1 to 5 ) which is greater than what was previously reported [34].

In many cases following cardiac surgery longer gait speed assessments may not be feasible, medically appropriate or safe. A shorter distance for testing gait speed like the 5 MWT may have a positive influence on the results and may be more inclusive for patients with physical limitations when longer test such as a 10MWT may exclude some patients who cannot consistently or safely ambulate that far [38]. Gait speed has been considered a 'vital sign' of physical function. Gait speeds of less than $0.92 \mathrm{~m} / \mathrm{s}$ have been associated with increased cardiovascular mortality in elderly adults. Due to the fact that gait speed is such a powerful predictor of mortality, it should be utilized to track progression in elderly individuals, including those with CVD $[39,40]$. Gait speed is reported to be cost effective, safe, with good accuracy, sensitivity, and time efficiency [41]. Gait speed has also been found to accurately predict post-hospitalization discharge location $78 \%$ of the time [42]. KB's gait speed upon discharge was $0.55 \mathrm{~m} / \mathrm{s}$, which is well below norms established for her age $[41,42]$. However, in a study involving elderly individuals, it was determined that gait speed change for small effects ranged from $0.04-0.06 \mathrm{~m} / \mathrm{s}$, while moderate effects ranged from $0.10-0.14 \mathrm{~m} / \mathrm{s}$ [43]. This further supports that KB's $0.25 \mathrm{~m} / \mathrm{s}$ increase in gait speed was clinically significant. The gait speed information obtained from the $5 \mathrm{MWT}$ could provide important information to develop the appropriate POC for the patient [44].

The FSS is a reliable and valid objective assessment tool which has been used primarily in those with Parkinson's disease (PD) patients, whose FSS scores were highly associated with the Parkinson Fatigue Scale, a specific measure for PD patients. Normative data were also established among a healthy elderly sample, with a mean improvement score of 2.3 (on a 1-7 scale, 7 being the most severe) [45]. The research done addressing the effectiveness, usefulness, and accuracy of the FSS in those with CVD is limited. In order to truly understand how KB's FSS score resulted in improved functional mobility, research must be conducted in older adults with CVD, particularly women in the acute care setting. Though KB's scores improved upon discharge, it is believed that she continues to experience from fatigue and needs further intervention [46].

As mentioned previously, one final objective measure that could potentially aid the examination of a patient with CVD is the KCCQ. This questionnaire gathers physical limitations as well as quantifies symptoms, social limitations, sense of self-efficacy, and quality of life. All of these factors have shown to provide researchers with sensitive, reliable and accurate measures to assist with the assessment of older adults with CHF. The score KB received on the KCCQ [45], places her at increased risk of mortality and re-hospitalization. In fact, it was found that for every 10-point decline in the overall KCCQ score from baseline, this equates to a $34 \%$ increased likelihood of dying within the next year. In addition, the patients with AS had very reliable outcomes from all domains, and the KCCQ was found to be highly reproducible in stable patients. Strong validity was also reported, while comparing the KCCQ to the 6MWT and NYHA classifications. Still, it was noted that there is an absence of appropriate reference standards to compare the various domains of the KCCQ [47]. This potential issue could be further resolved with additional research, specifically that addressing the elderly population with CVD and heart valve complications. Among other elderly patients, large beneficial changes were observed with chronic heart failure (CHF) due to completion of the KCCQ. This questionnaire gathers information on physical limitations as well as quantifies symptoms, social limitations, self-efficacy, and quality of life. All of these factors can provide researchers with sensitive, reliable and accurate measures for the assessment of older adults with CHF. The normative data found in elderly patients with CHF was associated with NYHA classifications and is as follows: 90-95 (NYHA I), 65-70 (NYHA II), 40 (NYHA III) and 20-25 (NYHA IV). Given these pre-existing norms, KB would be classified as having moderately severe CVD. However, further research is needed to examine KCCQ scores among elderly patients with CVD in an acute care setting [48].

Limited literature is available on the psychometric properties for most of the outcome measures utilized for examination and to guide intervention in this case report indicating the need to examine these measures in a more complex population of older adults. Research on appropriate outcome measures in this patient population in the acute care setting would be beneficial to PTs to further support evidence based practice. Additional data collection in later studies would provide imperative data for challenging cases like that of KB and help to advance the field of rehabilitation science.

\section{References}

1. DeTurk WE, Cahalin LP (2011) Cardiovascular and pulmonary physical therapy: An evidence based approach. 2nd edition. China: McGraw- Hill.

2. Horne Jr. A, Reineck EA, Hasan RK, Resar JR, Chacko M (2014) Transcatheter aortic valve replacement: Historical perspectives, current evidence, and future directions. $\mathrm{Am}$ Heart J 168: 414-423. [Crossref]

3. Czarny MJ, Resar JR (2014) Diagnosis and Management of Valvular Aortic Stenosis Clin Med Insights Cardiol 8: 15-24. [Crossref]

4. Nishimura RA, Otto CM, Bonow RO, Carabello BA, Erwin JP $3^{\text {rd }}$, et al. (2014) 2014 AHA/ACC guideline for the management of patients with valvular heart disease: Executive summary: A report of the American college of Cardiology/American heart association task force on practice guidelines. Circulation 129: 2440-2492. [Crossref] 
Fernandez N (2018) Acute care physical therapy management of a 69-year-old female following re-operative aortic valve replacement and tricuspid valve repair: A case report

5. Shan L, Saxena A, McMahon R, Wilson A, Newcomb A (2013) A systematic review on the quality of life benefits after aortic valve replacement in the elderly. $J$ Thorac Cardiovasc Surg 145: 1173-1189. [Crossref]

6. Adler J, Malone D (2012) Early Mobilization in the Intensive Care Unit: A Systematic Review. Cardiopulm Phys Ther J 23: 5-13. [Crossref]

7. Morris PE, Goad A, Thompson C, Taylor K, Harry B, et al. (2008) Early Intesive Care Unit Mobility Therapy in the Treatment of Acute Respiratory Failure. Crit Care Med 36: 2238-2243. [Crossref]

8. Macauley K (2012) Physical Therapy Management of Two Patients with Stage D Heart Failure in the Cardiac Medical Intensive Care Unit. Cardiopulm Phys Ther J 23: 37-45. [Crossref]

9. Mah JW, Staff I, Fichandler D, Butler KL (2013) Resource-efficient mobilization programs in the intensive care unit: who stands to win? Am J Surg 206: 488-493. [Crossref]

10. Brosseau L, Philippe P, Boulanger YL (1995) The Functional Independence Measure: Validity of selected assessment methods applied to stroke survivors. Top GeriatrRehab 11: 75-86.

11. Guide to physical therapist practice 3.0. 2014:1 online resource (2015).

12. Kiel MK (2011) Cardiac rehabilitation after heart valve surgery. PMR 3: 962-967. [Crossref]

13. Hanekom S, Gosselink R, Dean E, van Aswegen H, Roos R, et al. (2011) The Development of a Clinical Management Algorithm for Early Physical Activity and Mobilization of Critically Ill Patients: Synthesis of Evidence and Expert Opinion and its Translation into Practice. Clin Rehabil 25: 771-787. [Crossref]

14. Robicsek F, Fokin A, Cook J, Bhatia D (2000) Sternal instability after midline sternotomy. Thorac Cardiovasc Surg 48: 1-8. [Crossref]

15. Brocki BC, Thorup CB, Andreasen JJ (2010) Precautions related to midline sternotomy in cardiac surgery. A review of mechanical stress factors leading to sternal complications. Eur J Cardiovasc Nurs 9: 77-84. [Crossref]

16. Hanekom S, Gosselink R, Dean E, van Aswegen H, Roos R, et al. (2011) The Development of a Clinical Management Algorithm for Early Physical Activity and Mobilization of Critically Ill Patients: Synthesis of Evidence and Expert Opinion and its Translation into Practice. Clin Rehabil 25: 771-787. [Crossref]

17. Perme C, Chandrashekar R (2009) Early Mobility and Walking Program for Patients in Intensive Care Units: Creating A Standard of Care. Am J Crit Care 18: 212-221. [Crossref]

18. Bhattacharyya N, Baugh RF, Orvidas L, Barrs D, Bronston LJ, et al. (2008) Clinical practice guideline: benign paroxysmal positional vertigo. Otolaryngol Head Neck Surg 139: S47-S81. [Crossref]

19. Lawson J, Johnson I, Bamiou DE, Newton JL (2005) Benign paroxysmal positional vertigo: clinical characteristics of dizzy patients referred to a Falls and Syncope Unit. QJM 98: 357-364. [Crossref]

20. Guimarães MN, Almada Filho Cde M (2011) Functional status change in older adults undergoing coronary artery bypass surgery. Sao Paulo Med J 129: 99-106. [Crossref]

21. Green C, Porter CB, Bresnahan DR, Spertus JA (2000) Development and evaluation of the Kansas City Cardiomyopathy Questionnaire: a new health status measure for heart failure. J Am Coll Cardiol 35: 1245-1255. [Crossref]

22. Walke LM, Gallo WT, Tinetti ME, Fried TR (2004) The burden of symptoms among community-dwelling older persons with advanced chronic disease. Arch Intern Med 164: 2321-2324. [Crossref]

23. Kris AE, Dodd MJ (2004) Symptom experience of adult hospitalized medical-surgical patients. J Pain Symptom Manage 28: 451-459. [Crossref]

24. Hardy SE, Studenski SA (2008) Fatigue and Function over Three Years among Older Adults. J Gerontol A Biol Sci Med Sci 63: 1389-1392. [Crossref]

25. Dittner AJ, Wessely SC, Brown RG (2004) The assessment of fatigue: A practical guide for clinicians and researchers. $J$ Psychosom Res 56: 157-170. [Crossref]

26. Fritz S, Lusardi M (2009) White paper: walking speed the sixth vital sign. J Geriatr Phys Ther 32: 46-49. [Crossref]

27. Braden H (2012) Gait speed is limited but improves over the course of acute care physical therapy. J Geriatr Phys Ther 35: 140-144. [Crossref]

28. Bohannon RW, Williams Andrews A (2011) Normal walking speed: a descriptive meta-analysis. Physiotherapy 97: 182-189. [Crossref]
29. Purser JL, Weinberger M, Cohen HJ, Pieper CF, Morey MC, et al. (2005) Walking speed predicts health status and hospital costs for frail elderly male veterans. $J$ Rehabil Res Dev 42: 535-546. [Crossref]

30. Hardy SE, Perera S, Roumani YF, Chandler JM, Studenski SA (2007) Improvemen in usual gait speed predicts better survival in older adults. J Am Geriatr Soc 55: 17271734. [Crossref]

31. http://health.gov/paguidelines/guidelines/summary.aspx

32. Butchart EG, Gohlke-Barwolf C, Antunes MJ, Tornos P, De Caterina R, et al. (2005) Recommendations for the management of patients after heart valve surgery. Eur Heart J 26: 2463-2471.

33. Jones CJ, Rikli RE, Beam WC (1999) A 30-s chair-stand test as a measure of lower body strength in community-residing older adults. Res Q Exerc Sport 70: 113-119. [Crossref]

34. Beninato M, Gill-Body KM, Salles S, Stark PC, Black-Schaffer RM, et al. (2006) Determination of the Minimal Clinically Important Difference in the FIM Instrument in Patients With Stroke. Arch Phys Med Rehabil 87: 32-39. [Crossref]

35. Dakin L, Peel N (2011) Effect of accelerometry on the functional mobility of older rehabilitation inpatients as measured by functional independence measure locomotion (FIM) gain: A retrospective matched cohort study. J Nutr Health Aging 15: 382-386. [Crossref]

36. Tur BS, Gursel YK, Yavuzer G, Kucukdeveci A, Arasil T (2003) Rehabilitation outcome of Turkish stroke patients: in a team approach setting. Int J Rehabil Res 26 : 271-277. [Crossref]

37. Hobart JC, Lamping DL, Freeman JA, Langdon DW, McLellan DL, et al. (2001) Evidence-based measurement: which disability scale for neurologic rehabilitation? Neurology 57: 639-644. [Crossref]

38. Hsueh IP, Lin JH, Jeng JS, Hsieh CL (2002) Comparison of the psychometric characteristics of the functional independence measure, 5 item Barthel index, and 10 item Barthel index in patients with stroke. J Neurol Neurosurg Psychiatry 73: 188-190. [Crossref]

39. Wilson CM, Kostsuca SR, Boura JA (2013) Utilization of a 5-Meter Walk Test in Evaluating Self-selected Gait Speed during Preoperative Screening of Patients Scheduled for Cardiac Surgery. Cardiopulm Phys Ther J 24: 36-43. [Crossref]

40. Chen MA. Frailty and cardiovascular disease $\square$ potential role of gait speed in surgical ris stratification in older adults. 2015;12:44-56. [Crossref]

41. Bohannon RW (1997) Comfortable and maximum walking speed of adults aged 20-79 years: reference valves and determinants. Age Ageing 26: 15-19. [Crossref]

42. Rabadi MH, Blau A (2005) Admission ambulation velocity pre- dicts length of stay and discharge disposition following stroke in an acute rehabilitation hospital. Neurorehabil Neural Repair 19: 20-26. [Crossref]

43. Perera S, Mody SH, Woodman RC, Studenski SA (2006) Meaningful Change and Responsiveness in Common Physical Performance Measures in Older Adults. $J$ Am Geriatr Soc 54: 743-749. [Crossref]

44. Afilalo J, Eisenberg MJ, Morin JF, Bergman H, Monette J, et al. (2010) Gait speed as an incremental predictor of mortality and major morbidity in elderly patients undergoing cardiac surgery. J Am Coll Cardiol 56: 1668-1676. [Crossref]

45. Grace J, Mendelsohn A, Friedman JH (2007) A comparison of fatigue measures in Parkinson's disease. Parkinsonism Relat Disord 13: 443-445. [Crossref]

46. Fereshtehnejad S, Hadizadeh H, Farhadi F, Shahidi GA, Delbari A, et al. (2013) Reliability and validity of the persian version of the fatigue severity scale in idiopathic Parkinson's disease patients. Parkinsons Dis 2013: 935429. [Crossref]

47. Arnold SV, Spertus JA, Lei Y, Allen KB, Chhatriwalla AK, et al. (2013) Use of the Kansas City Cardiomyopathy Questionnaire for monitoring health status in patients with aortic stenosis. Circ Heart Fail 6: 61-67. [Crossref]

48. Green CP, Porter CB, Bresnahan DR, Spertus JA (2000) Development and evaluation of the Kansas City Cardiomyopathy Questionnaire: a new health status measure for heart failure. J Am Coll Cardiol 35: 1245-1255. [Crossref]

Copyright: (C2018 Fernandez N. This is an open-access article distributed under the terms of the Creative Commons Attribution License, which permits unrestricted use, distribution, and reproduction in any medium, provided the original author and source are credited. 